DE

M E D I C I N A

T R O P I C A L

$\mathrm{DE}$

SÃO PAULO

JOURNAL OF THE SÃO PAULO INSTITUTE OF TROPICAL MEDICINE

(1) Universiti Sains Malaysia, School of Biological Sciences

(2) Universiti Sains Malaysia, School of Biological Sciences, Vector Control Research Unit

Correspondence to: Wan Fatma Zuharah. Universiti Sains Malaysia, School of Biological Sciences, Minden, Penang 11800, Malaysia

Tel: +604-6536130, +604-5251525

E-mail:wfatma@usm.my

Received: 24 April 2016

Accepted: 22 September 2016

\section{Attraction factors for Paederus fuscipes' dispersal, a vector of Paederus dermatitis towards human residential premises}

\author{
Sufian Maryam', Nik Fadzly', Abdullah Al-Ashraf Amirul', Wan Fatma \\ Zuharah $^{1,2}$
}

\section{ABSTRACT}

Paederus fuscipes, a vector of Paederus dermatitis in most tropical and subtropical countries of the world have a high prevalence in human dwellings due to their positively phototaxic behaviour which has caused a tremendous impact on human health. In this paper, $P$. fuscipes dispersal flights were studied for two seasons of the rice cultivation phases in residential premises built close to rice field areas ( $\approx 32-60 \mathrm{~m}$ and $164 \mathrm{~m})$ in mainland Penang, Malaysia. We examined the effects of different light illuminance, building floor level and their association with rice stages as a focal cause of $P$. fuscipes dispersion from the rice fields towards human dwellings. The present study showed a significant interaction between different light illuminances and rice cultivation phases in attracting $P$. fuscipes to disperse and invade human dwellings. The highest number of $P$. fuscipes was captured near the bright light. $P$. fuscipes flights increased in line with each floor level, and the highest captures took place at higher building floor levels (levels 2 and 3) compared to lower building floor levels (ground floor and level 1) of a three storey apartment in both rice seasons. This finding not only conveys a better understanding on $P$. fuscipes dispersal pattern, but also draws public attention on the occurrence of dermatitis linearis caused by the Paederus beetles.

KEYWORDS: Built environment. Phototaxicity. Paederus. Rove beetle. Staphylinidae.

\section{INTRODUCTION}

About 50,000 staphylinid species are distributed worldwide ${ }^{1}$, with at least 650 species of the genus Paederus. These beetles are notoriously known to cause human health hazards due to its vesicant toxin hemolymph, pederin. Pederin inhibits mitosis in eukaryotic cells and triggers an offensive skin condition called Paederus dermatitis, or dermatitis linearis on affected human skin. This poisonous ant-like beetle is commonly distributed in the tropics and temperate regions ${ }^{2}$, and on all continents except Antarctica ${ }^{3}$.

In tropical countries, epidemics of dermatitis linearis have been frequently reported in Iran, Iraq, India, Pakistan, Sri Lanka and Southeast Asia. However, Paederus dermatitis is an extensively neglected insect-induced skin lesion especially in the tropics. Often neglected and seldomly reported, many go untreated due to unawareness of the skin condition ${ }^{4}$ as they are rather considered a common skin problem by the local residents ${ }^{5,6}$. Thus, many individuals do not seek treatment and have even ignored the symptoms. Only a small proportion of patients pursues medical care or is self-treated ${ }^{7}$. As a consequence, misdiagnosis can occur as the clinical appearance of Paederus dermatitis mimics many other dermatosis including herpes simplex, herpes zoster, phytophotodermatitis, acute allergic or other irritant 
dermatitis caused by some other venomous insects ${ }^{7,8,9,10}$. Interestingly, rove beetles do not display spontaneous bleeding effect as the Epicauta genus and they do not bite or sting. However, when a beetle is crushed on the skin surface, pederin is released causing the dermatitis ${ }^{7,11}$. They are also known to release the potent pederin when they are threatened, as a defensive response towards potential predators ${ }^{12}$.

Paederus is a nocturnal insect very stronlgly attracted by luminescent, fluorescent and neon lights that certainly and inadvertently bring the, near humans ${ }^{8,13}$. This is because brightly illuminated lamps from artificial light sources emitted by human residential premises attract Paederus beetles. In addition to those lights, long wave UV is found to be a factor that causes the attractiveness of beetles towards the light source ${ }^{14}$. This is true to most species of insects that are particularly sensitive to light of shorter wavelengths. Hence, well-lit premises at night in urban and suburban areas could inevitably attract them, resulting in high dermatitis infestation to individuals living nearby. For example, military operations that often involve the construction of bright lighted camps in Paederus endemic areas such as Paederus ilsae and Paederus iliensis in Iraq ${ }^{15}$, P. fuscipes in India ${ }^{16}$ and Pakistan ${ }^{17}$ were affected by the outbreaks of dermatitis linearis. Overall, it can be confirmed that most of the affected individuals worked near to artificial lightings at night.

Intermittent dermatitis cases have been reported in high-rise buildings in mainland Penang ${ }^{18}$. For these reasons, we sought to understand each floor level of an apartment building on Paederus dispersal flight pattern. Thus, the effect of different floor level has also being taken into account as one of the attraction factors for Paederus beetles to infest human dwellings. Generally, insects are known to take advantage of the wind to help them on their migratory flights. According to Drake \& Gatehouse ${ }^{19}$ and Chapman $e t$ $a l .^{20}$, the wind factor causes insects to frequently migrate to the higher altitudes of several meters above the ground and utilize fast moving airstreams to travel hundred kilometers in a single flight. Besides, flying at higher altitudes is a good migration approach which subsequently maximizes the insect population displacement, and helps finding suitable habitats to feed, mate and produce the next generation ${ }^{21}$.

Paederus fuscipes Curtis is the predominant Paederus species found mainly distributed in moist and damp conditions such as in rice fields of Malaysia ${ }^{22}$. Consequently, it is also noted that Paederus dermatitis cases in the Northern region of Peninsular Malaysia are more common in residential premises situated adjacent to the rice field areas ${ }^{18}$. Therefore, the present work aimed to investigate the effects of different light illuminance and the building floor level of a high-rise apartment during different rice cultivation phases as a focal cause of $P$. fuscipes beetles dispersion from the rice fields towards human dwellings.

\section{MATERIALS AND METHODS}

\section{Study Site}

Paederus fuscipes sampling started in October 2013 until October 2014 for one year period. Sampling was performed in two rice cultivation phases; Season 1 consisted of a five months sampling period from October 2013 to March 2014 (known as the main season) which coincided with the wet period, and Season 2 consisted of a seven month period from March 2014 to October 2014 (known as the off season) which coincided with the dry period. A complete cycle of rice cultivation phases consisted of (1) the ploughing stage, (2) the seeding stage, (3) the growing stage, and (4) the harvesting stage (Bong et al. $)^{18}$.

The study site was located at Jalan Sejahtera, Telok Air Tawar, Butterworth, Penang ( $5^{\circ} 29^{\prime} 9.3171^{\prime \prime} \mathrm{N}$, $100^{\circ} 23^{\prime} 1.3012$ " E). This sampling site is situated on the Northeastern coast of Peninsular Malaysia and has consistently warm and humid environment throughout the year with an annual rainfall of approximately $2,670 \mathrm{~mm}$. The temperature varies between $29-35^{\circ} \mathrm{C}$ during the day and $26-29^{\circ} \mathrm{C}$ at night. This site was chosen due to the highest infestation of $P$. fuscipes occurrence in mainland Penang which was based on the infestation report provided by the Seberang Perai city council department. In addition, rice fields are adjacent to the residential premises.

A three storey apartment $\left(5^{\circ} 29^{\prime} 8.9519^{\prime \prime} \mathrm{N}\right.$, $100^{\circ} 23^{\prime} 10.6481$ " E) and three landed houses, tagged as H1

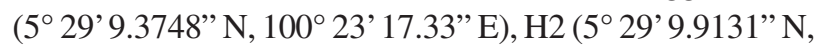
$\left.100^{\circ} 23^{\prime} 19.493^{\prime \prime} \mathrm{E}\right), \mathrm{H} 3\left(5^{\circ} 29^{\prime} 7.414^{\prime \prime} \mathrm{N}, 100^{\circ} 23^{\prime} 19.7633^{\prime \prime}\right.$ E) were selected as the study sites. The high-rise apartment building was approximately $164 \mathrm{~m}$ from the edge of the closest rice field, whereas the landed houses were between 32 and $60 \mathrm{~m}$ north to the boundary edge of the rice fields.

\section{Experimental design}

Effects of the light illuminance: Sticky trap size (Jamin, Seng Lee Trading) $18.9 \mathrm{~cm}$ (height) x $27.8 \mathrm{~cm}$ (length) was placed on each selected light source. These sticky traps were deployed on respectively three different light illuminance; (1) no light ( $\approx 0$ lux); where sticky traps were fixed surrounding fluorescent lamps that switched off their lights throughout the night, (2) low light ( $\approx 82$ lux); where sticky traps were fixed on the ceiling approximately $1.5 \mathrm{~m}$ away from the fluorescent lamp and this distance was selected because it is the furthest possible location from 
the light source which represents the lowest illuminance, and (3) bright light $(\approx 1,206$ lux $)$; where sticky traps were fixed surrounding the fluorescent lamp around $1 \mathrm{~cm}$ from the light source to represent the highest illuminance. The illuminance level was measured using a digital lux meter device (LX1010BS, China).

The first set of experiments was performed to determine the attractiveness of $P$. fuscipes beetles to the three different light illuminances on land residential premises. No light was represented by $\mathrm{H} 1$ and $\mathrm{H} 3$ of the land houses; low light was represented by the ground floor (level 0 ) of a three storey apartment, and bright light was represented by $\mathrm{H} 2$ of the landed houses including the ground floor (level 0) of the apartment. A different set of premises was used due to the lack of permission from the landlord to use their premises as an experimental site. Therefore, the ground floor (level 0 ) has the same level of landed houses was also included.

The second set of experiments was performed to determine the attractiveness of $P$. fuscipes beetles towards two different light illuminances based on different floor levels at the three storey apartment. Three sticky traps were placed at each low light and bright light illuminance on each floor level of the apartment building (level 0, level 1, level 2, level 3).

Effects of the building floor level: For this study, the experiment was conducted in a three storey apartment building. Six sticky traps were fixed on each floor of the three storey apartment building (level 0 , level 1, level 2 and level 3) surrounding fluorescent lamps. All of the trials were illuminated by ceiling-mounted white fluorescent lamp of MCF Model $(240 \mathrm{~V}, 50 \mathrm{~Hz}, 40 \mathrm{~W})$. After 24 hours, the first reading was taken and the subsequent readings were taken daily for three consecutive days every fortnight. Sticky traps were replaced at every sampling occasion. All of the trials were run using three replicates for each light illuminance. Samples of $P$. fuscipes at each floor were examined and counted using a blue Sharpie marker pen to avoid mistakes during calculation of the P. fuscipes' abundance. Comparisons were then made to estimate the number of beetles trapped on different floor levels of the three storey apartment.

\section{Statistical analysis}

All of the data were examined for distribution normality at a 5\% significance level by using the Shapiro-Wilk Normality test. A $\log 10$ transformation was performed to normalize the data to fulfill the assumption of the two-way analysis of variance ANOVA which was used to examine; (1) the effects of three different light illumination sources from the same floor level of land houses/ground floor apartments and rice cultivation phases; (2) the effects of two different light intensity sources at a three storey apartment with different floor levels; (3) the effects of three different floor levels of a three storey apartment and rice cultivation phases. Post hoc multiple comparisons were run to determine differences among the means by using the Tukey's honestly significant difference (HSD) test at $\alpha=0.05$. All the analyses were performed using the SPSS software, version 20.0. Data for rice cultivation phases in the main season and in the off season were analyzed separately as a comparison between two different rice seasons. One-way multivariate analysis of variance (MANOVA) was conducted to compare the number of captured beetles in a three storey apartment during the main season and the off season of the rice cultivation phases.

\section{RESULTS}

Effects of different light illuminances and building floor levels and association with rice cultivation phases

During the course of a year sampling period from October 2013 until October 2014, a total of 4,768 specimens of $P$. fuscipes beetle was collected from the residential premises throughout the main and the off rice seasons. A total of 1,279 beetles was captured in the main season (October 2013 - March 2014) of the rice cultivation phase. The highest number of beetles was captured during the harvesting stage totalling 728 individuals.

During the off season (March 2014 - October 2014) the number of captured beetles increased approximately three-fold, by 3,494 compared to the main season. The highest amount of beetles was 2,719 individuals during the rice growing stage. A statistically significant effect of rice cultivation phase on the number of captured $P$. fuscipes in the three storey high-rise apartment for both, the main and the off rice season was found throughout the one year sampling period $(\mathrm{F}=18.250 ; \mathrm{df}=6,14 ; p=0.000 ;$ MANOVA $)$.

\section{Effects of light illuminance and rice cultivation phases}

The attraction of $P$. fuscipes beetle towards the light differed significantly among the three different light illuminances $(\mathrm{F}=123.393 ; \mathrm{df}=2,48 ; p=0.000$; Table 1$)$. However, $P$. fuscipes was significantly more attracted towards sticky traps placed near the bright light compared to the low and to no light ( $p<0.05$; Fig. 1). Paederus fuscipes dispersion from the rice field towards the bright light found the highest number of trapped beetles with a total mean \pm SE of $20.4 \pm 25.92$. Conversely, P. fuscipes 
Table 1 - Effects of light illumination at the ground/ land floor level and rice cultivation phase on the dispersion of Paederus fuscipes beetles using two-way ANOVA.

\begin{tabular}{lccccc}
\hline Source & $\begin{array}{c}\text { Type III sum of } \\
\text { squares }\end{array}$ & df & Mean square & $\mathrm{F}$ & Sig. \\
\hline Rice Phase (RP) & 2.807 & 3 & 0.936 & 42.938 & 0.000 \\
Light illumination (LI) & 5.378 & 2 & 2.689 & 123.393 & 0.000 \\
RP X LI & 3.680 & 6 & 0.613 & 28.139 & 0.000 \\
\hline
\end{tabular}

* 'No light data were collected from $\mathrm{H} 1$ and $\mathrm{H} 3$ land houses. Whereas low light data from $\mathrm{H} 2$ and ground floor apartment and bright light data were collected from the ground floor of apartments.

Table 2 - Effects of three different light illumination at the ground/ land floor level and four rice stages on the dispersion of Paederus fuscipes beetle.

\begin{tabular}{lccc}
\hline \multirow{2}{*}{ Rice cultivation phase } & No light & Low light & Bright light \\
\cline { 2 - 4 } & Mean \pm SE & Mean \pm SE & Mean \pm SE \\
\hline Ploughing stage & $0.17 \pm 0.17^{\mathrm{aA}}$ & $0.0^{\mathrm{aA}}$ & $1.0 \pm 0.52^{\mathrm{bA}}$ \\
Seeding stage & $0.0^{\mathrm{aA}}$ & $0.0^{\mathrm{aA}}$ & $0.17 \pm 0.17^{\mathrm{bA}}$ \\
Growing stage & $0.17 \pm 0.17^{\mathrm{aB}}$ & $1.33 \pm 0.67^{\mathrm{aB}}$ & $11.83 \pm 1.38^{\mathrm{bB}}$ \\
Harvesting stage & $0.17 \pm 0.17^{\mathrm{aB}}$ & $0.67 \pm 0.33^{\mathrm{aB}}$ & $21.0 \pm 2.14^{\mathrm{bB}}$ \\
\hline
\end{tabular}

*Mean value within the same row (different light illumination) with different superscript small letters are significantly different ( $<<0.05$; ANOVA).

*Mean value within the same column (rice cultivation phase) with different superscript capital letter are significantly different $(\mathrm{p}<0.05 ;$ ANOVA).

* No light data were collected from $\mathrm{H} 1$ and $\mathrm{H} 3$ land houses, whereas low light data from $\mathrm{H} 2$ and ground floor apartment and bright light data were collected from ground floor of apartment.

seem to be the least attracted towards the low light and no light as the trapped insect counts on sticky traps placed on the same ground/ land floor level obtained the lowest weekly captures with total mean values \pm SE of $0.6 \pm 0.84$

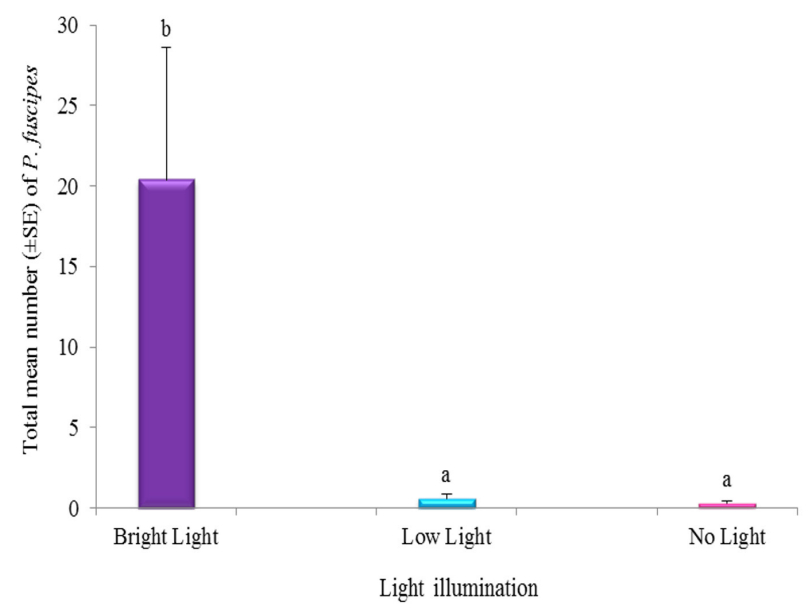

Figure 1 - Attraction of Paederus fuscipes beetles towards three different light illuminances at the same ground/land floor level. Data were expressed in mean \pm SE; bright light $(n=24)$, low light $(n=12)$, and no light $(n=24)$. Scale bars with the same letters showed no significant difference (Tukey's HSD; $p>0.05$ ). 'No light' data were collected from $\mathrm{H} 1$ and $\mathrm{H} 3$ land houses. Whereas 'low light' data from H2 and ground floor apartment and 'bright light' data were collected from ground floor of apartment. and $0.3 \pm 0.48$, respectively. No significant differences were found for both, no light and low light illuminance, for all the rice cultivation phases $(p>0.05$; Table 2$)$.

However, there was a significant interaction found between different light illuminance at the same floor level and rice cultivation phase in attracting adult $P$. fuscipes to disperse from the rice field and invade human residential premises $(\mathrm{F}=28.139 ; \mathrm{df}=6,48 ; p=0.000$; Table 1$)$. The number of beetles captured in the low light has slightly increased during the growing and harvesting stages compared to the other rice cultivation phase. However, bright lights have captured significantly higher numbers of $P$. fuscipes beetles for all the rice cultivation phases, particularly during the growing and harvesting stages of the rice crop $(p<0.05$; Table 2$)$.

\section{Effects of different floor levels and rice cultivation phases}

Paederus fuscipes was strongly attracted to the higher level compared to the lower level of the three storey apartment building throughout the main and the off rice seasons ( $p<0.05$; Fig. 2a and Fig. 2b). Overall, significantly more beetles were collected at level 3 during the whole sampling period. 
During the main rice season, the number of $P$. fuscipes differed significantly among the different floor levels of the three storey apartment $(\mathrm{F}=41.290 ; \mathrm{df}=3,32 ; p=0.000$; Table 3). Paederus fuscipes flights towards each floor increased linearly from the lowest to the highest floor of the apartment building with a total mean of $11.8 \pm 13.08$ at level $0 ; 20.8 \pm 24.67$ at level $1 ; 38.9 \pm 51.80$ at level 2; and $46.9 \pm 49.04$ at level 3 .

Paederus fuscipes dispersal flight towards human
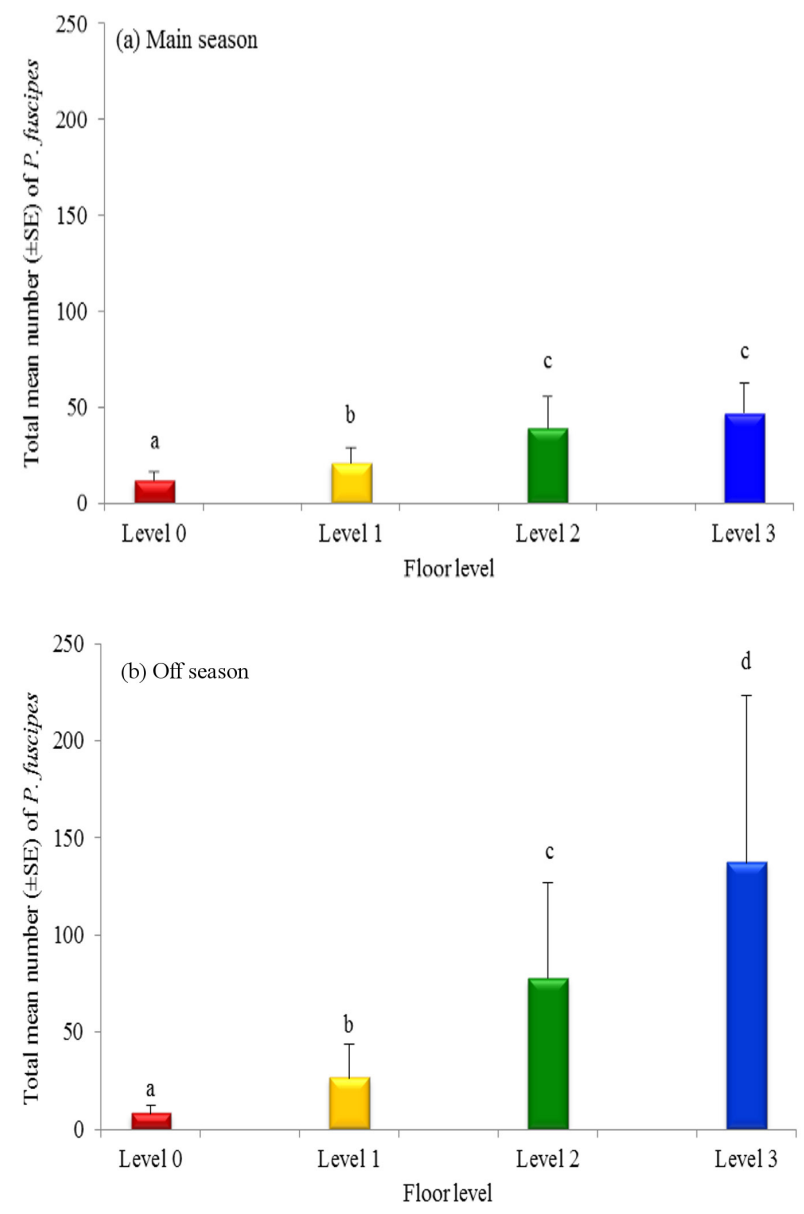

Figure 2 - Attraction of Paederus fuscipes beetles towards different floor levels of a three storey apartment during (a) the main season and $(b)$ the off season of the rice cultivation phases. Data were given in mean \pm SE $(n=12)$. Scale bars with the same letters showed no significant difference (Tukey's HSD; $p>0.05)$. residential premises was also significantly affected by the rice cultivation phases $(\mathrm{F}=313.808, \mathrm{df}=3, p=0.00$; Table 3$)$. During the ploughing stage, the highest number of beetles was captured at level 3 with a mean of $14.33 \pm 0.58$. However, the present study showed no significant difference between both level 2 and level 3 of the high-rise apartment $(p>0.05$; Table 4). There was also no significant interaction found between the different building floor level of the three storey apartment and the rice cultivation phase of the main rice season $(\mathrm{F}=1.763$, $\mathrm{df}=9,32 ; p=0.115$; Table 3$)$.

During the off rice season, a significant difference was also found in P. fuscipes dispersion between different floor levels of the three storey apartment $(\mathrm{F}=90.500 ; \mathrm{df}=3$, 32; $p=0.000$; Table 5). Most $P$. fuscipes were captured from the top floor at level 3 compared to the other levels. Captured beetles increased gradually from the lowest to the highest floor with a total mean of $8.14 \pm 15.85$ at level $0 ; 26.5 \pm 64.83$ at level 1; $77.64 \pm 183.86$ at level 2 and $137.29 \pm 322.72$ at level 3 of the three storey apartment.

The number of beetles in residential premises was affected by the rice cultivation phases $(\mathrm{F}=397.735, \mathrm{df}=3$, $p=0.000$; Table 5). More beetles were captured during the ploughing stage due to the prolonged ploughing period. A significant abundance of captured P. fuscipes was found throughout the rice growing stages at all levels of the high-rise building ( $p>0.05$; Table 6$)$. On this rice season, a significant interaction was found between different floor levels of the three storey apartment and rice cultivation phase $(\mathrm{F}=6.686 ; \mathrm{df}=9,32 ; p=0.000$; Table 5).

\section{Effects of light illuminance at a three storey apartment}

At different levels of the apartment building, bright light has also received the highest quantity of trapped beetles at all floor levels of the three storey apartment with a total mean number of $108.3 \pm 124.28$ during the main rice season. Unlike the bright light, low light has only captured a smaller amount of beetles with a total mean number of $10.1 \pm 12.7$. No light was discarded in this analysis due to very the insufficient number of captured beetles in the previous experiment.

In general, our results indicated that the dispersion of beetles towards the apartment building increased in

Table 3 - Effects of floor level and rice cultivation phase differences on the dispersion of Paederus fuscipes beetles during the rice main season using two-way ANOVA.

\begin{tabular}{lccccc}
\hline Source & $\begin{array}{c}\text { Type III sum of } \\
\text { squares }\end{array}$ & df & Mean square & F & Sig. \\
\hline Rice Phase (RP) & 15.546 & 3 & 5.182 & 313.808 & 0.000 \\
Floor Level (FL) & 2.046 & 3 & 0.682 & 41.290 & 0.000 \\
RP X FL & 0.262 & 9 & 0.029 & 1.763 & 0.115 \\
\hline
\end{tabular}


Table 4 - Effects of different floor levels and four rice stages on the dispersion of Paederus fuscipes beetle during the main rice season.

\begin{tabular}{lcccc}
\hline \multirow{2}{*}{ Rice cultivation phase } & Level 0 & Level 1 & Level 2 & Level 3 \\
\cline { 2 - 5 } & Mean \pm SE & Mean \pm SE & Mean \pm SE & Mean \pm SE \\
\hline Ploughing stage & $2.0 \pm 0.58^{\mathrm{aA}}$ & $3.67 \pm 1.76^{\mathrm{bA}}$ & $5.0 \pm 1.0^{\mathrm{cA}}$ & $14.33 \pm 0.33^{\mathrm{cA}}$ \\
Seeding stage & $0.33 \pm 0.33^{\mathrm{aB}}$ & $0.67 \pm 0.33^{\mathrm{bB}}$ & $1.67 \pm 0.33^{\mathrm{cB}}$ & $1.67 \pm 0.33^{\mathrm{cB}}$ \\
Growing stage & $14.67 \pm 0.33^{\mathrm{aC}}$ & $28.33 \pm 2.96^{\mathrm{bC}}$ & $50.0 \pm 7.37^{\mathrm{cC}}$ & $50.33 \pm 5.78^{\mathrm{cC}}$ \\
Harvesting stage & $22.33 \pm 3.33^{\mathrm{aD}}$ & $36.67 \pm 3.18^{\mathrm{bD}}$ & $73.0 \pm 10.02^{\mathrm{cD}}$ & $89.67 \pm 7.31^{\mathrm{cD}}$ \\
\hline
\end{tabular}

${ }^{*}$ Mean value within the same row (different floor level) with different superscript small letters are significantly different ( $p<0.05$; ANOVA). *Mean value within the same column (rice cultivation phase) with different superscript capital letters are significantly different $(p<0.05$; ANOVA $)$.

Table 5 - Effects of floor levels and rice cultivation phase differences on the dispersion of Paederus fuscipes beetles during the rice off season using two-way ANOVA.

\begin{tabular}{lccccc}
\hline Source & $\begin{array}{c}\text { Type III sum of } \\
\text { squares }\end{array}$ & df & Mean square & F & Sig. \\
\hline Rice Phase (RP) & 24.090 & 3 & 8.030 & 397.735 & 0.000 \\
Floor Level (FL) & 5.481 & 3 & 1.827 & 90.500 & 0.000 \\
RP X FL & 1.215 & 9 & 0.135 & 6.686 & 0.000 \\
\hline
\end{tabular}

Table 6 - Effects of different floor levels and four rice stages on the dispersion of Paederus fuscipes beetle during the rice off season.

\begin{tabular}{lcccc}
\hline \multirow{2}{*}{ Rice cultivation phase } & Level 0 & Level 1 & Level 2 & Level 3 \\
\cline { 2 - 5 } & Mean \pm SE & Mean \pm SE & Mean \pm SE & Mean \pm SE \\
\hline Seeding stage & $0.33 \pm 0.33^{\mathrm{aA}}$ & $0.00 \pm 0.00^{\mathrm{bA}}$ & $0.67 \pm 0.33^{\mathrm{cA}}$ & $1.33 \pm 0.67^{\mathrm{dA}}$ \\
Ploughing stage & $5.33 \pm 0.33^{\mathrm{aB}}$ & $12.00 \pm 2.65^{\mathrm{bB}}$ & $28.33 \pm 3.28^{\mathrm{cB}}$ & $45.67 \pm 4.91^{\mathrm{dB}}$ \\
Harvesting stage & $6.33 \pm 1.2^{\mathrm{aC}}$ & $15.00 \pm 3.21^{\mathrm{bC}}$ & $46.00 \pm 9.71^{\mathrm{cC}}$ & $97.33 \pm 14.1^{\mathrm{dC}}$ \\
Growing stage & $25.67 \pm 6.33^{\mathrm{aD}}$ & $96.67 \pm 8.84^{\mathrm{bD}}$ & $287.33 \pm 8.69^{\mathrm{cD}}$ & $496.33 \pm 47.88^{\mathrm{dD}}$ \\
\hline
\end{tabular}

${ }^{*}$ Mean value within the same row (different floor level) with different superscript small letters are significantly different $(p<0.05$; ANOVA). *Mean value within the same column (rice cultivation phase) with different superscript capital letters are significantly different $(p<0.05 ;$ ANOVA).

line with different floor levels. The maximum number of P. fuscipes was found on level 3 of the three storey apartment near the bright light with a mean number of $42.8 \pm 45.44$. Conversely, the lowest mean number of $P$. fuscipes was recorded in low light on the ground floor (level 0) of the apartment with a mean of $0.6 \pm 0.84$ individuals. However, no significant difference was found between the captured beetles on level 2 and level 3 for both bright light and low light illuminances ( $p>0.05$; Fig. 3a). Overall, no significant interaction was found during the main rice season on the number of captured beetles near light illuminances on each different floor level of the high-rise apartment on the dispersion of $P$. fuscipes towards human dwellings $(\mathrm{F}=0.710 ; \mathrm{df}=3,16 ; p=0.560$; Table 7).

During the rice off season, the number of captured beetles by sticky traps located on all floor levels near the bright light showed a total mean number of $220.29 \pm 525.95$ individuals, followed by the low light with a total mean number of $29.29 \pm 62.64$. Level 3 had the highest number of captured beetles by sticky traps placed adjacent to the bright light with a mean number of $117.57 \pm 279.07$. Conversely, sticky traps placed near the low light at level 0 captured only $0.5 \pm 1.40$ individuals. Thus, a significant difference was found between the captured beetles on all floor levels of the apartment building for both bright light and low light illuminances $(p<0.05$; Fig. $3 b)$. Due to greatest difference in the number of beetles captured at this rice season, a significant interaction was found between light illuminance at different floor levels of the high-rise apartment on $P$. fuscipes dispersal towards human dwellings $(\mathrm{F}=3.916 ; \mathrm{df}=3,16 ; p=0.029 ;$ Table 7$)$.

\section{DISCUSSION}

The primary reason why these insects come out in the evening from their foraging sites in the rice field and invade residential premises during twilight is because they are drawn to the artificial lights produced by the light bulbs. Our results indicate that bright light has a profound impact on $P$. fuscipes dispersal flights towards human dwellings. 
Table 7 - Effects of light illumination at different floor levels of a three storey high-rise apartment building on the dispersion of Paederus fuscipes beetles using two-way ANOVA.

\begin{tabular}{lcccccc}
\hline Rice season & Source & $\begin{array}{c}\text { Type III sum of } \\
\text { squares }\end{array}$ & df & Mean square & F & Sig. \\
\hline \multirow{3}{*}{ Main season } & Light Illumination (LI) & 6.443 & 1 & 6.443 & 293.006 & 0.000 \\
& Floor Level (FL) & 1.629 & 3 & 0.543 & 24.698 & 0.000 \\
\hline \multirow{3}{*}{ Off season } & LI X FL & 0.047 & 3 & 0.016 & 0.710 & 0.560 \\
& Light Illumination (LI) & 6.160 & 1 & 6.160 & 443.042 & 0.000 \\
& Floor Level (FL) & 6.738 & 3 & 2.246 & 161.537 & 0.000 \\
\hline
\end{tabular}
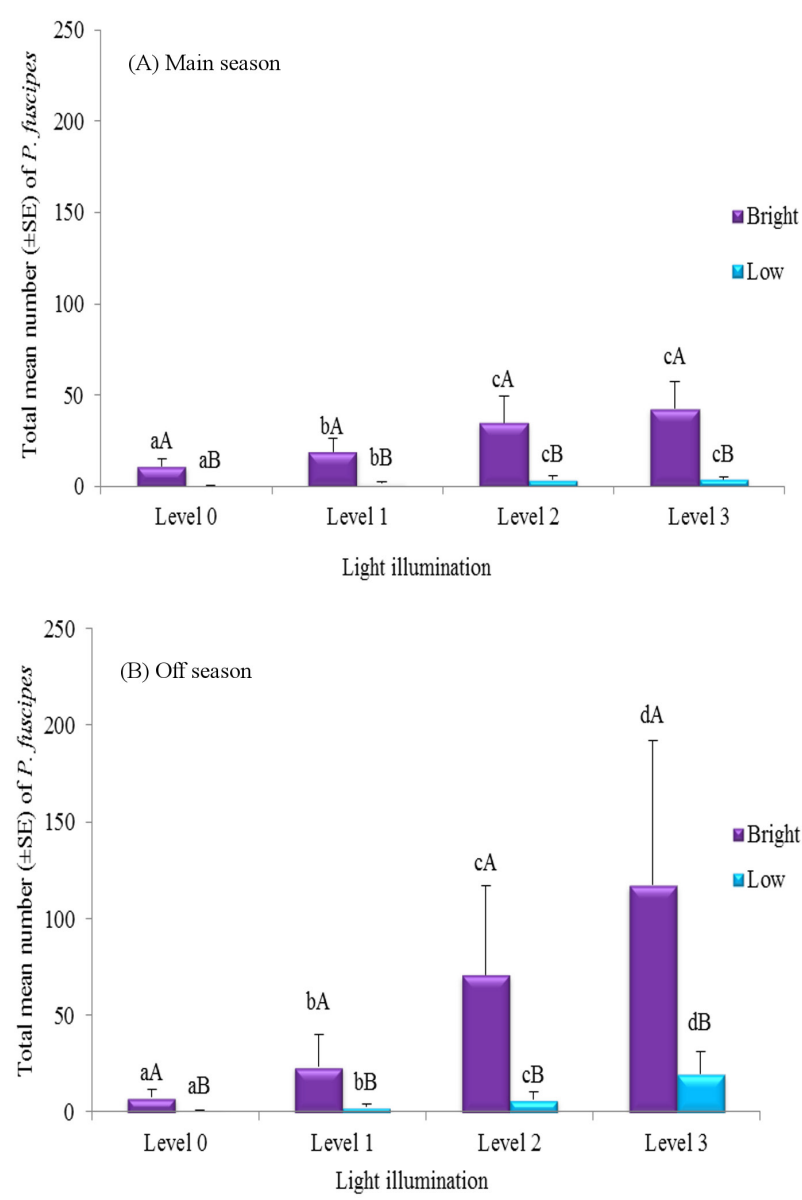

Figure 3 - Attraction of $P$. fuscipes beetles towards two different light illuminances at different floor levels of an apartment building during (a) the main season, and (b) the off season. The lowercase letter refers to the comparison between floor levels, whereas the uppercase letter refers to the comparison between two light illuminances on the dispersion of $P$. fuscipes. Scale bars with the same letters are not significantly different (Tukey's HSD; $p>0.05$ ).

Most circumstances that trigger outbreaks are at high-rise apartments particularly during rice growing and harvesting stages. Most recently, Heo et al. ${ }^{6}$ stated that P. fuscipes are night-flying insects and are extremely attracted by bright illuminances after dusk. Paederus fuscipes positive phototaxis behaviour is an advantage as artificial lighting tend to attract other insect species from the rice field such as the rice pest making them easy preys due to their vulnerability to predation.

Paederus fuscipes rove beetles are the prevalent species and lavishly found in Malaysian rice fields as an aggressive predator of the rice pests ${ }^{22}$. Therefore, our study was conducted in residential buildings nearby rice fields because P. fuscipes epidemics were mostly reported in people living adjacent to rice field areas. Paederus flew to residential premises during the nocturnal period due to light attraction, suggesting a higher possibility of infection by Paederus dermatitis during the night time. However, dermatitis lesions could also happen during the day time whenever a Paederus beetle is still present inside the residential house. In Malaysia, major $P$. fuscipes outbreaks in human dwellings occurred next to rice fields as reported in Kelantan ${ }^{23}$ and Terengganu ${ }^{24}$.

Besides Malaysia, other countries all over the world have also similar problems regarding Paederus sp. invasions particularly for people living nearby moisty and condensed vegetated areas such as rice agricultural farms ${ }^{25}$. Approximately $62 \%$ of hostel pupils residing near rice fields were affected by dermatitis linearis in a suburban teaching hospital in Kanchipuran, India ${ }^{26}$. Other similar reported cases of P. fuscipes attacks in India were further supported by data from the study of Gnanaraj et al. ${ }^{27}$ and $\mathrm{Gopal}^{28}$.

Our study has also found that the light factor plays an important role in attracting $P$. fuscipes beetles to disperse towards human dwellings. This statement can be further supported by an infestation of beetles in a well illuminated hospital in Sri Lanka ${ }^{26}$ and in a toy building factory in central China, all due to good lighting conditions at night ${ }^{29}$. In South Sudan, Iserson et al. ${ }^{30}$ reported that due to the use of bright lights in a house compound area, an individual developed a skin lesion known as the "Nairobi fly rash" (also known as Paederus dermatitis) caused by the Paederus beetles. Our study has proved that $P$. fuscipes adults flight can even be stimulated by the light illumination from the residential areas located many miles away from their natural habitats. In this current study, the residential premises were about 32-60 $\mathrm{m}$ and $164 \mathrm{~m}$ distant from the nearest rice field, 
but they could still attract the flight dispersal of $P$. fuscipes towards the land houses and the high-rise apartments. Warrant and McIntyre ${ }^{31}$ indicated that insects living in low light environment surroundings have compounded eyes that confer a superior sensitivity to a wide range of light sources, a similar situation experienced by $P$. fuscipes populations living in low light conditions of rice fields.

Nocturnal insects are known to have enhanced sensitivity towards light sources ${ }^{32}$. Thus, P. fuscipes were found to be attracted to both bright and low illuminances throughout this study. However, the highest number of beetles was captured near the bright light compared to the low light due to the brightness (luminous intensity) and illuminance (luminous flux density) that $P$. fuscipes senses in space. Consequently, to minimize the contact with Paederus beetle, it is advised to use low intensity lighting during the night time, especially in human dwellings situated near rice field areas, as the current study showed that light illuminance has caused an attraction of $P$. fuscipes and they flew towards human residential premises.

Attraction of $P$. fuscipes towards human residential premises has also been influenced by the type of lighting used for illuminance as revealed by Lima et al. ${ }^{33}$. According to Briscoe and $\mathrm{Chittka}^{34}$, the insect vision perceives three specific colors of the ultraviolet, blue or green, while red or infrared lights emitted by the tungsten incandescent light bulb are invisible to certain insect species. Paederus fuscipes are mostly found attracted to fluorescent lightings instead of tungsten filament incandescent light bulbs ${ }^{35}$. During our experiment on the dispersal of beetles towards human dwellings, fluorescent lamps were predominantly used for lighting in all landed houses and high-rise apartment building . Hence, this could be another factor that attracts beetles to invade housing areas as fluorescent lamps contain low pressure mercury-vapor gas that produces a small amount of short wave ultraviolet lights ${ }^{33}$ or sometimes has a tinge of blue or green in color that is perceived by most insects.

According to Huang et al. ${ }^{29}$ the victims of dermatitis linearis were mainly those living in apartments at the top and middle levels compared to the bottom level. The results of our study on P. fuscipes dispersal pattern at different floor levels are in line with previous reports in the literature. The present study found that higher floor level have significantly more beetle infestation compared to the lower floor levels of the three storey high-rise apartment. Besides, a reported dermatitis epidemic occurred at a higher floor level apartment buildings in Penang in the year of 2002 where thousands of high-rise apartment residents were affected by the invasion of $P$. fuscipes beetles ${ }^{24}$. Subsequently, living in high-rise building is associated with a greater risk of acquiring dermatitis linearis from Paederus beetles as found in our study. Henceforth, an approach to reduce the chances of becoming Paederus dermatitis victims, residents of upper floor levels are particularly advised to take appropriate precaution measures, such as reducing light utilization and the intensity at night, to lower the risk of Paederus dermatitis.

Pedgley ${ }^{36}$ stated that dispersion of insects at long distances by the large-scale of wind system is a common initial factor of agricultural pests or insect-borne infections outbreaks. Thus, most insects, particularly those that are passive fliers are benefited by the wind factor to fly at heights of more than a few hundred meters above the ground level, involving them in high-altitude flights ${ }^{19,37}$. The findings of this study showed that the preference of $P$. fuscipes to fly at the higher floor levels of the high-rise apartments may be entirely due to the wind-assisting migration from the rice fields. According to $\mathrm{Drake}^{38}$, the number of infestation at a given altitude level also depends on the atmospheric stability in nature favoring flight activities.

P. fuscipes dispersal flight from the rice field towards human residential areas was also prompted by the rice cultivation phases. Throughout this experimental study, the number of captured beetles was the highest during the growing and harvesting stages in both rice seasons. On the contrary, an extremely low number of beetles was found to disperse towards the residential buildings during the rice seeding stage. According to Bong et al..$^{18}$, P. fuscipes flight dispersal was primarily initiated once their habitats in the rice field were severely destroyed by farmers, particularly during the harvesting stage when the rice stalks and straws were cut and eventually burned.

Consequently, adult beetles might migrate and seek refuge when their breeding habitat is disturbed, which is unsuitable for beetle's harborage. Some of them will even disperse towards nearby rice crops at other rice plots that have not yet been harvested or towards other immediate places. Hossain et al..$^{39}$ claimed that the adult pests of Helicoverpa spp. including the natural enemies dispersed from harvested towards unharvested alfalfa to seek refuge as an immediate response to harvesting. This showed that habitat manipulation has indeed increased as a natural enemy as well as native pest abundance and movement. Moreover, in the absence of beetle favorable dense vegetation environment in the rice field for their breeding grounds, P. fuscipes are easily drawn towards luminescent and fluorescent light sources at human residential premises during night time especially when rice crop has been harvested ${ }^{40}$.

Dispersal of $P$. fuscipes from the rice field was also due to host/ prey shortages following the rigorous disturbance and decimation of rice fields caused by human activities. According to Van Driesche and Bellows ${ }^{41}$, agronomic 
practices also affect predator-prey interaction in crop fields. Paederus fuscipes is an important predator on many rice pest species in the rice field area ${ }^{42}$. Small phytophagous insects are generally consumed by the P. fuscipes beetles ${ }^{22}$. Hence, as the population of pests has massively decreased as a consequence of the destruction of crop vegetation at harvest, these polyphagous predators will move to other suitable places. The searching for food supply in other close areas to support their population needs to survive, has inadvertly brought $P$. fuscipes in contact with human beings due to light attraction at night, thus triggering dermatitis linearis outbreaks. Dermatitis linearis may occur when the adult beetle lands on human skin, and by trying to remove it physically, humans provoke the release of the toxic fluid known as pederin ${ }^{43}$. According to Veraldi et al. ${ }^{44}$, the exposed skin area has neutrophils and necrotic vesicles which are normally observed during the progress of the dermatitis.

Once rice seeds were sowed during the rice seeding stage, both populations of rice pests and predators will massively migrate back to the rice fields. The population of both predator and pest increased more abundantly during the rice vegetative stage, and later dispersed to human residential premises towards lights during the night time ${ }^{15}$. As a result, the number of captured beetles at residential houses also rises significantly throughout the rice growing stage apart from regular high capture rates during the harvesting phase.

Paederus fuscipes flight dispersal from the rice field towards human dwelling was primarily stimulated during the growing and harvesting stages of the rice crop. Most beetle infestation occurred when artificial lights of greater light illuminances were used, and people were at home after nightfall. Overall, significantly more beetles were captured at the highest floor level of the high-rise apartments as $P$. fuscipes flight took place at higher altitude levels while flying to avoid impending obstacles in the environment. Consequently, standard precautions need to be taken particularly during both, growing and harvesting rice stages, to reduce the risk of Paederus dermatitis outbreaks. The fact that the least illuminated residence had the lowest captured number of beetles suggests that lower light intensity bulbs should be used to reduce the probability of Paederus infestations. Hence, the most efficient light source that could be introduced for lighting purposes is the LED lamp that uses less energy to function, thus the luminous flux is lower compared to those of fluorescent lights.

\section{ACKNOWLEDGEMENTS}

We are grateful to all the staffs from the School of Biological Sciences, Universiti Sains Malaysia that were involved in this project, especially to Prof. Lee Chow Yang and Prof. Salmah Md Rawi for their valuable advice. Also to the students of the Medical Entomology Laboratory, Universiti Sains Malaysia for their assistance in the field. This research was funded by the Research University Grant USM (1001/PBIOLOGI/811284) and the graduate financial support from the Ministry of Higher Education, Malaysia for Maryam Sufian.

\section{CONFLICT OF INTEREST}

The authors declare that there are no conflicts of interest.

\section{REFERENCES}

1. Grebennikov VV, Newton AF. Good-bye Scydmaenidae, or why the ant-like stone beetles should become megadiverse Staphylinidae sensu latissimo (Coleoptera). Eur J Entomol. 2009;106:275-301.

2. Bong LJ, Neoh KB, Jaal Z, Lee CY. Paederus outbreaks in human settings: a review of current knowledge. J Med Entomol. 2015;52:517-26.

3. Frank JH. Paederus sensu lato (Coleoptera: Staphylinidae): an index and review of the taxa. Insecta Mundi. 1988;2:97-159.

4. Taneja A, Nayak S, Shenoi SD. Clinical and epidemiological study of Paederus dermatitis in Manipal, India. J Pak Assoc Dermatol. 2013:23:133-8.

5. Sendur N, Savk E, Karaman G. Paederus dermatitis: a report of 46 cases in Aydın, Turkey. Dermatology. 1999;199:353-5.

6. Heo CC, Latif B, Hafiz WM, Zhou HZ. Dermatitis caused by Paederus fuscipes Curtis, 1840 (Coleoptera: Staphilinidae) in student hostels in Selangor, Malaysia. Southeast Asian J Trop Med Public Health. 2013;44:197-205.

7. Zargari O, Kimyai-Asadi A, Fathalikhani F, Panahi M. Paederus dermatitis in northern Iran: a report of 156 cases. Int J Dermatol. 2003;42:608-12.

8. Frank JH. Kanamitsu K. Paederus sensu lato (Coleoptera: Staphylinidae): natural history and medical importance. J Med Entomol. 1987;24:155-91.

9. Haddad V Jr, Cardoso JL, Lupi O, Tyring SK. Tropical dermatology: Venomous arthropods and human skin: Part I. Insecta. J Am Acad Dermatol. 2012;67:331.

10. Gopal KV. Paederus dermatitis: a clinical, epidemiological and therapeutic study of 417 cases. J Evol Med Dent Sci. 2014;3:4736-43.

11. Khan TM, Hassali MA, Gillani SW, Hameed MA. Clinical presentation of "Rove beetle dermatitis". Australas Med J. 2009;1:19-24

12. Mammino JJ. Paederus dermatitis: an outbreak on a medical mission boat in the Amazon. J Clin Aesthet Dermatol. 2011;4:44-6. 
13. Morsy TA, Arafa MA, Younis TA, Mahmoud IA Studies on Paederus alfierii Koch (Coleoptera:Staphylinidae) with special reference to the medical importance. J Egypt Soc Parasitol. 1996;26:337-51.

14. Nikbakhtzadeh MR, Tirgari S. Medically important beetles (Insecta: Coleoptera) of Iran. J Venom Anim Toxins incl Trop Dis. 2008;14:597-618.

15. Davidson SA, Norton SA, Carder MC, Debboun M. Outbreak of dermatitis linearis caused by Paederus ilsae and Paederus iliensis (Coleoptera: Staphylinidae) at a military base in Iraq. US Army Med Dep J. 2009 Jul-Sep;6-15.

16. Verma CR, Argawal S. Blistering beetle dermatitis: an outbreak. Med J Armed Forces India. 2006;62:42-4.

17. Dursteler BB, Nyquist RA. Outbreak of rove beetle (Staphylinid) pustular contact dermatitis in Pakistan among deployed U.S. personnel. Mil Med. 2004;169:57-60.

18. Bong LJ, Neoh KB, Lee CY, Jaal Z. Dispersal pattern of Paederus fuscipes (Coleoptera: Staphylinidae: Paederinae) in relation to environmental factors and the annual rice crop cycle. Environ Entomol. 2013;42:1013-9.

19. Drake VA, Gatehouse AG, editors. Insect migration: tracking resources through space and time. Cambridge: Cambridge University Press; 1995.

20. Chapman JW, Reynolds DR, Smith AD, Smith ET, Woiwod IP. An aerial netting study of insects migrating at high altitude over England. Bull Entomol Res. 2004;94:123-36.

21. Gatehouse AG. Behaviour and ecological genetics of wind-borne migration by insects. Ann Rev Entomol. 1997;42:475-502.

22. Manley GV. Paederus fuscipes (Col.: Staphylinidae): a predator of rice fields in west Malaysia. Entomophaga. 1977;22:47-59.

23. Mokhtar N, Singh R, Ghazali W. Paederus dermatitis among medical students in USM, Kelatan. Med J Malaysia. 1993;48:403-6.

24. Rahmah E, Norjaiza MJ. An outbreak of Paederus dermatitis in a primary school, Terengganu, Malaysia. Malays J Pathol. 2008;30:53-6.

25. Ali A, Sujitha K, Devika T, Sivasankaran MP, Balan K, Saleem $\mathrm{M}$, et al. A study on Paederus dermatitis outbreak in a suburban teaching research hospital, Kanchipuram, India. Med-Science. 2013;2:764-9.

26. Kamaladasa SD, Perera WD, Weeratunge L. An outbreak of Paederus dermatitis in a suburban hospital in Sri Lanka. Int J Dermatol. 1997;36:34-6.

27. Gnanaraj P, Venugopal V, Mozhi MK, Pandurangan CN. An outbreak of Paederus dermatitis in a suburban hospital in South India: a report of 123 cases and review of literature. J Am Acad Dermatol. 2007;57:297-300.

28. Gopal KV. Paederus dermatitis: a clinical, epidemiological and therapeutic study of 417 cases. J Evol Med Dent Sci. 2014;3:4736-43.
29. Huang C, Liu Y, Yang J, Tian J, Yang L, Zhang J, et al. An outbreak of 268 cases of Paederus dermatitis in a toy-building factory in central China. Int J Dermatol. 2009;48:128-31.

30. Iserson KV, Walton EK. Nairobi fly Paederus dermatitis in South Sudan: a case report. Wilderness Environ Med. 2012;23:251-4.

31. Warrant EJ, McIntyre PD. Strategies for retinal design in arthropod eyes of low F-number. J Comp Physiol A. 1991;168:499-512.

32. Nilsson DE. Optics and evolution of the compound eye. In: Stavenga DG, Hardie R, editors. Facets of vision. Berlin: Springer; 1989. p.30-73.

33. Lima DC, Costa AA, Silva FS. Abundance and night hourly dispersal of the vesicating beetles of the genus Paederus (Coleoptera, Staphylinidae) attracted to fluorescent, incandescent and black light sources in the Brazilian savanna. J Med Entomol. 2015;52:50-5.

34. Briscoe AD, Chittka L. The evolution of color vision in insects. Annu Rev Entomol. 2001;46:471-510.

35. Verma S, Gupta S. Ocular manifestations due to econda (Paederus sabaeus). Med J Armed Forces India. 2012;68:245-8.

36. Pedgley DE. Windborne pests and diseases: meteorology of airborne organisms. Chichester: Ellis Horwood; 1982.

37. Chapman JW, Reynolds DR, Smith AD. Vertical-looking radar: a new tool for monitoring high-altitude insect migration. BioScience. 2003;53:503-11.

38. Drake VA. The influence of weather and climate on agriculturally important insects: an Australian perspective. Austr J Agric Res. 1994;45:487-509.

39. Hossain Z, Gurr GM, Wratten SD, Raman A. Habitat manipulation in lucerne Medicago sativa: arthropod population dynamics in harvested and 'refuge' crop strips. J Appl Ecol. 2002;39:44554.

40. Hanna HM, Hamad NE. Flight of Paederus alfierii Koch, at different heights. Bull Soc Entomol Egypte. 1975;59:345-54.

41. Thies C, Haenke S, Scherber C, Bengtsson J, Bommarco R, Clement LW, et al. The relationship between agricultural intensification and biological control: experimental tests across Europe. Ecol Appl. 2011;21:2187-96.

42. Kalshoven LG. Pests of crops in Indonesia. Jakarta: Ichtiar Baru; 1981.

43. Lamme EN, van Leeuwen RT, Jonker A, van Marle J, Middelkoop E. Living skin substitutes: survival and function of fibroblasts seeded in a dermal substitute in experimental wounds. J Invest Dermatol. 1998;111:989-95.

44. Veraldi S, Uka E, Chiaratti A, Nazzaro G, Gianotti R, Suss L. Paederus fuscipes dermatitis: a report of nine cases observed in Italy and review of the literature. Eur J Dermatol. 2013;23:38791. 